(b) Une liaison covalente phosphodiester s'établit entre l'hydroxyle en position $2^{\prime}$ de l'adénosine du site de branchement et le phosphate de l'extrémité 5 ' libre de l'intron, établissant la structure branchée schématisée dans le cadre. Dans les acides nucléiques, la succession des nucléosides se fait par l'intermédiaire de ponts phosphodiesters entre les hydroxyles $5^{\prime}$ et $3^{\prime}$ des riboses adjacents. Le lasso se forme par établissement de cette liaison inhabituelle $5^{\prime}-2^{\prime}$.

(c) Le site accepteur d'épissage est précisément clivé, une liaison s'établissant entre l'hydroxyle libre $3^{\prime}$ de l'exon $A$ et le phosphate $5^{\prime}$ de l'exon $\mathrm{B}$.

Les produits de la réaction sont l'intron avec sa structure branchée en lasso, qui sera probablement dégradé, et les deux exons correctement liés.

3. Rôle (s) et anomalies de l'épissage: le rôle des introns est inconnu, mais il est impératif qu'ils soient excisés de l'ARN, car ils ne peuvent pas être traduits en protéine et, s'ils étaient présents dans le messager cytoplasmique, ils introduiraient des arrêts précoces de la traduction, et donc de la synthèse des protéines. Des mutations peuvent modifier les signaux indispensables à l'épissage, ou encore faire apparaître dans les exons ou les introns de nouveaux sites de coupure. Les conséquences de ces anomalies peuvent être une dégradation rapide de l'ARN incapable de subir sa maturation normale, ou l'arrivée dans le cytoplasme d'ARN qui ne peuvent être traduits en la protéine biologiquement active

A.K.

Les nouvelles

de ce numéro

ont été préparées par :

J. C. Dreyfus

A. Kahn

J. P. Grunfeld

Serge Erlinger

\section{Résistance à /'alcool, enzymes et mutations}

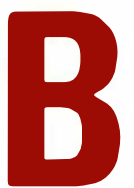

es différences de tolérance à l'alcool, tant individuelles qu'ethniques sont bien connues. Rougeur faciale, élévation thermique, accélération du rythme du pouls et de la respiration sont particulièrement fréquentes chez les Orientaux et notamment dans la population japonaise.

Le métabolisme de l'alcool est sous la dépendance immédiate de deux enzymes, l'alcool déshydrogénase et l'aldéhyde déshydrogénase. Ces deux enzymes comportent plusieurs systèmes d'allèles et de nombreux polymorphismes. L'alcool déshydrogénase forme un complexe de trois loci gouvernant trois chaînes protéiques dotées de variants alléliques. L'un d'eux, le locus $\mathrm{ADH}_{2}$, est d'un intérêt particulier parce que ses divers phénotypes sont doués de propriétés catalytiques différentes. Un variant $\beta_{2} \beta_{2}$ fréquent chez les Orientaux, differe du type habituel $\beta_{1} \beta_{1}$ des Caucasiens. Une mutation unique en position 47 (arg $\rightarrow$ lys) modifie l'affinité et le mode de fixation du coenzyme NAD. Il en résulte une double modification fonctionnelle, abaissant le $\mathrm{pH}$ optimum de ro vers la zone plus physiologique de 8,5 , et accélérant la vitesse de réaction. Les sujets porteurs de ce variant oxydent donc plus vite l'alcool en acétaldéhyde que ceux porteurs de l'allèle habituel. Ils représentent près de $90 \%$ des Orientaux et moins de $5 \%$ des Occidentaux. L'aldéhyde déshydrogénase existe sous deux formes, $\mathrm{ALDH}_{1}$ cytosolique, et $\mathrm{ALDH}_{2}$ mitochondriale. Environ $50 \%$ des Orientaux (Chinois, Japonais, Indiens) possèdent seulement l'isozyme majeur $\mathrm{ALDH}_{1}$ et n'ont pas d'activité $\mathrm{ALDH}_{2}$. La molécule d'ALDH $\mathrm{H}_{2}$ est présente car elle est immunologiquement reconnaissable mais elle est inactive. Yoshida et coll. ont réussi à purifier les enzymes normale et inactive et à montrer qu'une mutation ponctuelle (glu $\rightarrow$ lys) était la cause de cette inactivation. La présence des deux aldéhydes déshydrogénases est nécessaire pour une oxydation correcte de l'acétaldéhyde. $\mathrm{ALDH}_{1}$ a une forte affinité pour son coenzyme NAD mais faible pour son substrat, alors que c'est l'inverse pour $\mathrm{ALDH}_{2}$. Si l'on admet avec la plupart des auteurs que l'acétaldéhyde est toxique, on voit que les Orientaux cumulent deux inconvénients : leur alcool déshydrogénase, trop active, en produit en excès; leur aldéhyde déshydrogénase, déficiente, est incapable de les en débarrasser. De telles mutations, ou d'autres conduisant à des effets analogues, sont rares en Occident mais peuvent exister, et l'on a par exemple décrit une alcool déshydrogénase "Berne " dont les propriétés sont identiques à celles de $\mathrm{l}^{\prime} \mathrm{ADH}_{2}$ "Orientale ". Si donc vous vous trouvez à table en face d'une personne qui semble mal supporter l'alcool, rien ne vous empêche d'imaginer la structure des enzymes qui sont probablement responsables de ce comportement...

J.C.D.

Jörnvall H, Hempel J, Vallee BL, Bosron WF, Li TK. Human liver alcool dehydrogenase: aminoacid substitution in the $\beta_{2} \beta_{2}$ Oriental isozyme explains functional properties, establishes active site structure, and parallels mutational exchanges in the yeast enzyme. Proc Natl Acad Sci USA 1984; 81 : 3024-8.

Yoshida A, Huang IY, Ikawa M. Molecular abnormality of an inactive aldehyde dehydrogenase variant commonly found in Oriental. Proc Natl Acad Sci USA 1984; 81 : 258-6r.
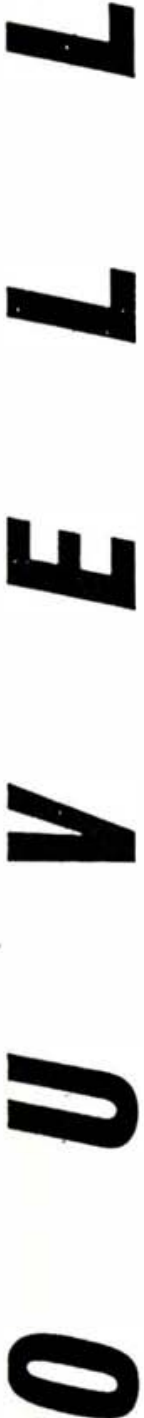


\section{Publier ou vendre?}

'érythropoiétine est une hormone glycoprotéique qui stimule la production des globules rouges par les précurseurs érythroblastiques en réponse à une hypoxie. Ni la structure exacte, ni même les sites électifs de synthèse de cette hormone n'étaient connus avec certitude, quoique des arguments convergents indiquaient qu'elle était synthétisée notamment dans le rein et le foie. Or, la carence en érythropoïétine pourrait jouer un rôle déterminant dans l'anémie des insuffisants rénaux. Dans le numéro du 28 février 85 de Nature, des chercheurs de la firme privée Genetic Institute (Boston, Mas, USA) rapportent la première caractérisation certaine du gène et de l' $A D N$ complémentaire codant pour l'hormone [I]. Des éléments partiels de séquence protéique ont permis de synthétiser des sondes oligonucléotidiques qui ont été utilisées pour cribler des banques d'ADN génomique. Un fragment $d u$ gène a ensuite servi de sonde pour cribler une banque d'ADN complémentaire de l'ARN de foie fotal et des clones correspondant à toute la séquence du messager ont été isolés et séquencés, permettant de déduire la structure primaire complète de la protéine. Il est évident que ces travaux ouvrent la voie à la production d'érythropoiétine par recombinaison génétique, l'intérêt thérapeutique potentiel de l'hormone étant grand. Or, dans le même numéro de Nature, on peut lire une publicité d'une autre firme de génie génétique, qui propose... de l'érythropoiétine humaine produite par recombinaison génétique. L'une publie, l'autre vend!

A.K.

1. Facobs $K$, Shoemaker $C$, Rudersdorf $R$, et al. Isolation and characterization of genomic and cDNA clones of human erythropoietin. Nature 2985; 313: 806-ro.

\section{Une nouvelle épidémie de l'Oural à I'Atlantique?}

C 'est à l'occasion de la guerre de Corée que la médecine occidentale a appris à connaître la fièvre hémorragique avec syndrome rénal (FHSR) : la maladie a atteint plusieurs milliers de soldats coréens et américains. En fait les FHSR sont bien plus anciennes, décrites depuis I9I3, sous diverses dénominations, en URSS ou en Chine, touchant chaque année plusieurs milliers de personnes. La maladie était également connue en Europe, en Scandinavie depuis I 934 sous le terme de néphropathie épidémique, en Europe centrale et dans les Balkans. Il est enfin possible que les "néphrites dites de guerre" observées en Europe dans les tranchées, pendant le premier conflit mondial, aient été des FHSR. En 1976 , le virus responsable de la fièvre hémorragique coréenne a été identifié et dénommé virus de Hantaan, du nom de la rivière qui coule près du $38^{\mathrm{e}}$ parallèle entre la Corée du Nord et la Corée du Sud. Ce virus à ARN appartient à la famille des Bunyaviridae; il a été démontré par la suite que la plupart des fièvres hémorragiques étaient dues au même virus ou à des virus apparentés qu'on a proposé de regrouper sous le nom générique de Hantavirus. Plusieurs rongeurs sont les réservoirs du virus et l'homme se contamine par inhalation des déjections des rongeurs.

Depuis I 983 , la maladie est apparue en Europe occidentale, dans la région parisienne puis en Belgique. De nombreux autres cas ont été rapportés dans l'Est et le Nord de la France, aux Pays-Bas, et récemment, en Ecosse. Les données cliniques et virologiques sont résumées dans l'excellente revue de Van Ypersele de Strihou, Van der Groen et Desmyter [Actualités Néphrologiques de l'Hôpital Necker, I985, Flammarion, Paris (sous presse)]. La maladie se marque au début par de la fièvre avec bradycardie relative, suivie de douleurs abdominales et/ou lombaires, puis d'une insuffisance rénale aiguë souvent précédée par une protéinurie abondante. L'atteinte rénale est due à une néphrite interstitielle aiguë. L'insuffisance rénale est réversible en quelques jours ou semaines, et la dialyse peut être nécessaire. En Europe occidentale, comme en Scandinavie mais à l'inverse de ce qu'on observe en Extrême-Orient, la mortalité est très faible, inférieure à o,5-I \%; les manifestations hémorragiques sont discrètes, limitées à une hémorragie conjonctivale chez $6 \%$ environ des malades; une thrombopénie passagère est présente dans 20 à $50 \%$ des cas.

L'apparition de la FHSR en Europe occidentale reflète-t-elle l'extension de l'épidémie à partir de la Scandinavie et de l'Europe orientale, ou ne résulte-t-elle que de l'identification précise d'une maladie ancienne mais jusqu'alors méconnue ? La question mérite d'être posée. En effet la sérologie permet aujourd'hui de faire le diagnostic de l'infection à Hantavirus et de rattacher de façon rétrospective à la FHSR des cas d'insuffisance rénale aiguë dont la cause n'avait pu être trouvée, ou encore qui avaient été rapportés (sans preuve formelle) à une leptospirose ou à une glomérulonéphrite aiguë dite épidémique.

La FHSR s'observe surtout en milieu rural (y compris chez les citadins qui s'adonnent aux travaux dans les greniers et les caves de leurs résidences secondaires...). La maladie peut également s'observer dans les villes, comme Seoul ou Osaka, par l'intermédiaire des rats. Les rats enfin peuvent être à l'origine d'épidémies parmi les sujets travaillant dans des laboratoires de recherche utilisant des animaux contaminés. La FHSR est aujourd'hui bien identifiée; il reste à en connaître mieux l'épidémiologie en Europe occidentale pour adapter les moyens de lutte. 